\title{
Passive Acoustic Monitoring and Automatic Detection of Diel Patterns and Acoustic Structure of Howler Monkey Roars
}

\author{
Leandro A. Do Nascimento ${ }^{1,2, *(\mathbb{D})}$, Cristian Pérez-Granados ${ }^{3} \mathbb{D}$ and Karen $H$. Beard $^{1}$ (D) \\ 1 Department of Wildland Resources and the Ecology Center, Utah State University, Logan, UT 84322, USA; \\ karen.beard@usu.edu \\ 2 Instituto de Desenvolvimento Sustentável Mamirauá, Tefé 69553-225, AM, Brazil \\ 3 Ecology Department/IMEM “Ramón Margalef”, Universidad de Alicante, 03690 Alicante, Spain; \\ cristian.perez@ua.es \\ * Correspondence: le_nasc@hotmail.com
}

check for updates

Citation: Do Nascimento, L.A.; Pérez-Granados, C.; Beard, K.H. Passive Acoustic Monitoring and Automatic Detection of Diel Patterns and Acoustic Structure of Howler Monkey Roars. Diversity 2021, 13, 566. https://doi.org/10.3390/ d13110566

Academic Editor: Michael Wink

Received: 14 October 2021

Accepted: 3 November 2021

Published: 5 November 2021

Publisher's Note: MDPI stays neutral with regard to jurisdictional claims in published maps and institutional affiliations.

Copyright: (c) 2021 by the authors. Licensee MDPI, Basel, Switzerland. This article is an open access article distributed under the terms and conditions of the Creative Commons Attribution (CC BY) license (https:// creativecommons.org/licenses/by/ $4.0 /)$.

\begin{abstract}
Nighttime studies are underrepresented in ecological research. Even well-known behaviors, such as the loud call of howler monkeys, are rarely studied at night. Our goal was to help fill this knowledge gap by studying the $24 \mathrm{~h}$ vocal behavior of the Guianan red howler monkey (Alouatta macconnelli) and to compare the acoustic structures of howling bouts made during the day to those made at night. We used passive acoustic monitoring coupled with automatic acoustic detection to study three groups of howlers over three months in the Viruá National Park, Roraima, Brazil. The automatic classifier we built detected 171 howling bouts with a $42 \%$ recall rate and $100 \%$ precision. Though primarily diurnal, howlers vocalized mainly at night. Greater vocal activity before nautical twilight might be associated with territorial and resource defense behaviors, with howlers calling from roosting sites before starting their daily routines. We also found that during the day, howling bouts were longer and had lower harmonic-to-noise ratios, lower frequencies, and more symmetric energy distributions than bouts at night. Our study adds to growing evidence that passive acoustic monitoring and automatic acoustic detection can be used to study primates and improve our understanding of their vocal behavior.
\end{abstract}

Keywords: passive acoustic monitoring; automatic acoustic classification; diel cycle; roars; vocal behavior; loud calls; howler monkeys; template detection; nighttime ecology

\section{Introduction}

Howler monkeys (Alouatta spp.) emit the most powerful primate vocalization in the Neotropics, which may outperform all animals worldwide in both call duration and amplitude per body size [1]. These loud calls are thought to have multiple functions [2]. For example, loud calls may reduce predation risk, facilitate group cohesion, mediate sexual selection by male-male competition or female choice, and regulate intergroup use of space [2-5]. Despite the large interest in these remarkable loud calls, several species of howler monkeys still lack acoustic characterization of their calls [2,6,7]. Even less is known about the nocturnal vocal activity of howlers because most studies focus on their diurnal behaviors $[1,2,5]$.

The fact that howler loud calls are rarely studied at night is not surprising because nighttime studies are, in general, underrepresented in ecological research [8,9]. For example, calls from birds and primates, two of the most studied animal taxa, are mostly studied during the day because it is easier to collect daytime data and because researchers often assume diurnal animals are not active at night, despite the lack of empirical support for this assumption [8-14]. Anthropoids, except the genus Aotus, are considered diurnal. However, there are reports of several anthropoids, such as mantled howler monkeys (Alouatta palliata), black-and-gold howler monkeys (Alouatta caraya), red-tailed monkeys (Cercopithecus ascanius), chimpanzees (Pan troglodytes), Ugandan red colobus monkeys (Procolobus rufomitratus 
tephrosceles), and Guianan red howler monkeys (Alouatta macconnelli) showing nocturnal activity $[5,10,14-16]$. Diurnal sample bias $[8,9]$ may preclude appreciation that species thought to be strictly diurnal are active during the full diel cycle [11-14].

Even though the loud calls of Guianan red howler monkeys were described almost three decades ago in French Guiana [15], constraints with software and recording equipment limited both spectrogram analysis and the number of calls analyzed. Nonetheless, it has been suggested that loud calls differed at different times of day, especially in regard to call duration [15]. Previous studies on other primates, such as Venezuelan howlers (Alouatta seniculus) and mantled howlers, also found acoustic differences between loud calls produced early in the morning and those produced over the day [17-19]. To the best of our knowledge, none of the previous studies were specifically designed to test for differences in call structure in howler monkeys across the full diel cycle.

Emerging new technologies and techniques, such as passive acoustic monitoring (PAM) and automatic acoustic detection of calls [20-22], greatly facilitate studying soundproducing animals at night and have the potential to advance both behavioral ecology and conservation practices [23-25]. Recently, researchers have used PAM and automatic classifiers to decipher diel and annual vocal cycles of black-and-gold howlers and mantled howlers $[5,26]$ and expanded upon the number of acoustic features analyzed for black howlers (Alouatta pigra) and mantled howlers [6,7]. These studies highlighted the utility of PAM and automatic acoustic detection of calls as promising methods to monitor primates and improve understanding of their vocal behavior. However, the number of studies assessing the utility of those techniques for monitoring non-flying mammals is still very limited (ca. $6 \%$ of the total of studies, see review for terrestrial wildlife in [21]).

Here, we employed PAM coupled with automatic acoustic detection to investigate the diel pattern of vocal activity of the Guianan red howler monkey and improve knowledge about its call structure and vocal behavior. Specifically, our goals were: (1) to investigate whether PAM and automatic acoustic detection of calls might be useful to monitor the vocal behavior of the species in a biodiversity hotspot in northern Brazil where automatic detection may be problematic due to saturated soundscapes, and (2) to determine if the acoustic structure of howling bouts made during the day were different from those made at night. This study is important because it elucidates the diel vocal behavior of a poorly studied Neotropical primate through emerging new technologies to monitor biodiversity while also providing insight about differences in nocturnal and diurnal loud calls, an understudied topic in ecology [8].

\section{Materials and Methods}

\subsection{Study Area and Groups}

We conducted this research in Viruá National Park (VNP), Roraima state, Brazil (Figure S1). The park was established in 1998 and is 240,000 ha [27]. VNP is regulated by flood pulses that create a rich habitat mosaic ranging from dense forest to grassland [25,27]. The region is characterized by a warm and wet climate with mean annual temperatures around $26{ }^{\circ} \mathrm{C}$ and mean annual precipitation of $\sim 2000 \mathrm{~mm}$ [27]. The wet season extends typically from May to September and the dry season from October to April [27]. We conducted this study primarily in terra-firme forest, a habitat located at elevations higher than surrounding lands (ca. $100 \mathrm{~m}$ a.s.l.) and, therefore, is not susceptible to intense flooding during the wet season [27].

From February to April 2018 (dry season), we followed three groups of Guianan red howler monkeys with roughly six individuals each (Table 1). Groups were followed by two experienced observers using binoculars at ca. $100 \mathrm{~m}$ distances and hidden in the forest. This totaled about 300 contact hours for each group because there were days we did not follow any group due to weather conditions or other scientific activities. Individuals in the groups were photographed and were mainly differentiated by their size and sex. During this period, we collected their position with a handheld GPS whenever they moved away 
from roosting and feeding sites, so that we could estimate the size of the area each group occupied, which was a mean area of 1.64 ha (Table 1).

Table 1. Composition and size of occupied areas for the three groups of Guianan red howler monkeys monitored in Viruá National Park, Brazil. Infants were of unknown sex and were identified because they were still riding on female backs. Subadults were identified by their smaller size than fully developed adults.

\begin{tabular}{ccccccc}
\hline Group Name & Adult Male & Adult Female & Male Subadult & Infant & Total & Occupied Area (ha) \\
\hline Calados & 1 & 4 & 1 & 1 & 7 & 0.66 \\
Pequi & 1 & 3 & 1 & 1 & 6 & 0.93 \\
Viruá & 1 & 3 & 1 & 1 & 6 & 3.35 \\
\hline
\end{tabular}

Like other howler species, Guianan red howler monkeys engage in howling bouts (Figure 1) that consist of a series of continuous roars, a type of loud call described as lowpitched sounds with a mean duration of $3 \mathrm{~min}$ and $28 \mathrm{~s}$ and a range from 1 to $10 \mathrm{~min}$ [15]. Guianan red howlers produce another type of loud call, referred to as a bark, which usually is not mixed with roars during howling bouts in South American howler species [1]. Therefore, we did not consider barks in our study but only howling bouts consisting of roars. The alpha male in howler groups always roars, but the other group members' (including females) participation in howling bouts is facultative [1]. By sex, there are differences between roars uttered by males and females, and female calls are poorly studied [1].

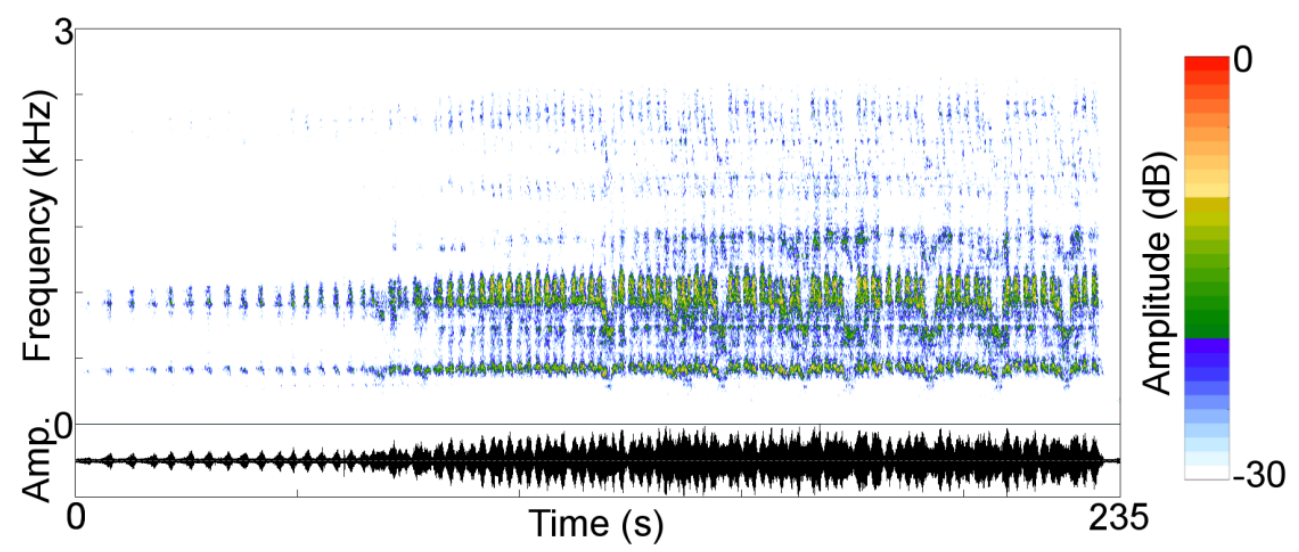

Figure 1. Audiospectrogram (Frequency) and oscillogram (Amplitude) of a typical howling bout of the Guianan red howler monkey in Viruá National Park, Roraima, Brazil.

\subsection{Passive Acoustic Monitoring Protocol}

We used six ARBIMON recorders [28] to collect acoustic data from February to April 2018. We deployed two recorders in each of the living areas of the three groups of howlers surveyed (Pequi, Viruá, and Calados). Each group was on average $933 \mathrm{~m}$ apart from each other as estimated by the centroids of their occupied areas. The recorders were placed where individuals in the group were most often seen eating and sleeping. Preliminary data collected in 2017 [25] along with local knowledge of field assistants aided in the placement of the recorders. We placed recorders, programmed to record $24 \mathrm{~h}$ per day in 20-min segments (sample rate: $44.1 \mathrm{kHz}$, resolution: 16-bit, WAV format) on trees $1.5 \mathrm{~m}$ off the forest floor. Recorders were synchronized to record simultaneously across the studied groups. We checked recorders every two days, retrieved the recordings, and then re-attached them to the trees. During the study period, we never observed invasion of a territory by a neighboring group, and by comparing the time of simultaneous recording in the different areas with field observations, we are confident that the recordings used in subsequent analyses belonged to the focal groups studied. 


\subsection{Automatic Detection and Diel Vocal Behavior}

First, to build a classifier to detect howling bouts automatically in our PAM dataset, we manually annotated 10 randomly selected days of recordings $(720 \mathrm{~h})$ from each studied group using the Audacity software [29]. We applied a $5 \mathrm{~dB}$ gain filter to all recordings to better visualize the spectrograms and listened to the audio files to capture all howling bouts present in the recordings and to create our validation dataset (gold standard, containing 146 howling bouts).

Second, using the R package MonitoR [30], we constructed a template (Figure S2) that was representative of howling bouts and the soundscape in which it was embedded [31,32]. We then used this template to build an automatic classifier to scan the whole dataset looking for the target signal. Detection scores vary from -1 to 1 , where 1 indicates a perfect correlation between template and sound events (peaks). Following the threshold applied in previous studies [31,32], we set the detection score to 0.4 to filter detections with low similarities with the templates (false positives). The automatic detection consisted of a comparison of the spectral and temporal features of the template with the recording at different time lags $(t)$ through a non-overlapping moving window $(S)$. The comparison between template $(k)$ and recording was achieved with a cross-correlation at each time lag where both templates and recording were converted to a short-term Fourier transform with a Hanning window size of 512 samples. The implementation of this workflow in the MonitoR package is based on the following equation [33]:

$$
d(t)=\sum_{t 1} \sum_{f} S(t+t 1, f) k(t 1, f)
$$

where $d(t)$ is the detection score at each time $t, S$ is the spectrogram in which signals will be detected through each time interval $t+t 1$ and frequencies $f$, and $k$ is the template kernel used for the detection.

Third, to evaluate the automatic detection classifier we matched the validation dataset (gold standard) with the predictions (automatic classification). We obtained a table (Table 2) with four categories of detections: true positive (TP), true negative (TN), false positive (FP), and false negative (FN). We calculated two metrics to evaluate the detector's performance, the recall rate $(\mathrm{TP} /(\mathrm{TP}+\mathrm{FN})$ and precision $(\mathrm{TP} /(\mathrm{TP}+\mathrm{FP})$. The recall rate indicates how well the segmentation algorithm detects sounds of interest, and the precision indicates how reliable the detector is [34].

Table 2. Detection categories evaluating the automatic classification of howling bouts of the Guianan red howler monkey.

\begin{tabular}{ccccc}
\hline & True Positive & True Negative & False Positive & False Negative \\
\hline Detections & 61 & 2039 & 0 & 85 \\
\hline
\end{tabular}

Fourth, to determine the diel vocal behavior of the Guianan howler monkey, we ran the automatic classifier in the full dataset consisting of $\sim 5400 \mathrm{~h}$ of recordings. We retrieved the total number of howling bouts detected per hour (all groups pooled) to elucidate which hour of the day the howlers were most vocally active.

\subsection{Acoustic Parameter Extraction Protocol}

Howling bouts were classified as diurnal or nocturnal according to the time of day they were recorded. We considered the nocturnal period to be from nautical twilight in the evening to nautical twilight in the morning $[13,35,36]$. Due to the low variation in twilight timing during the study, we considered those recordings made between $1900 \mathrm{~h}$ to $0529 \mathrm{~h}$ to be nocturnal, while those made between $0530 \mathrm{~h}$ to $1859 \mathrm{~h}$ to be diurnal. We randomly selected an even number of high-quality (i.e., limited background noise) howling bouts recorded during the day and during the night (Figure S3 for spectrograms examples). The distance from vocalizing animals to recorders was estimated to be on 
average $20 \mathrm{~m}( \pm 5 \mathrm{~m})$ for the selected howling bouts based on field observations of animals never leaving sleeping trees at night and foraging in known areas close to recorders during the day, but also on the sound pressure level (i.e., non-degraded) of the recorded signals, and comparing the sound pressure level of the selected howling bouts with a dataset of howling bouts previously recorded at a known distance. Based on these assumptions, we selected 34 howling bouts for each group to analyze for a total of 51 nocturnal and 51 diurnal bouts (Pequi: 20 nocturnal and 14 diurnal; Viruá: 20 nocturnal and 14 diurnal; Calados: 11 nocturnal and 23 diurnal). We used a maximum of two bouts from each group each night or day (separated by more than one hour when in the same day) to minimize dependence among the samples (see Figure S4 for temporal distribution of selected howling bouts). We controlled background noise by selecting recordings with no other sound-producing animals in the background and with very limited abiotic sounds (e.g., rain, wind, etc.). To confirm that background noise levels were similar between day and night recordings, we used the $\mathrm{R}$ package Seewave [37] to calculate the mean frequency spectrum (mean relative amplitude of the frequency distribution) in 1-s audio clips of silence from immediately before and after 15 nocturnal and 15 diurnal howling bouts selected randomly across the 102 howling bouts analyzed (Figure S5).

We extracted nine acoustic features from selected howling bouts (see definitions in Table 3). We drew spectrograms with a fast Fourier transformation (FFT), Hanning window type, and a time window of 512 points to measure their mean frequency, median frequency, dominant frequency, skewness, and kurtosis of howling bouts; this was completed in the $R$ package Seewave [37]. We also drew spectrograms with an FFT, Gaussian window type, $0.1 \mathrm{~s}$ window length, a $50 \mathrm{~dB}$ dynamic range, a maximum formant of $4000 \mathrm{~Hz}$, and resolutions of 1500 time steps and 250 frequency steps to measure the first formant, the highest frequency (sixth formant), and the harmonic-to-noise ratio (a measure of deterministic chaos; [38]); this was achieved using Praat 6.1 software [39] and following methodology similar to Bergman et al. [6] and Dunn et al. [40] for the construction of spectrograms and extraction of formants (Figure S6). Individual roar syllables were used in Praat from the middle section of the full howling bout sequence for consistency across all recordings. Finally, the duration of the bouts was measured manually in seconds using the Audacity software [29]. We used R 4.0.0 version and Audacity 2.4.1 in all analyses.

Table 3. Acoustic parameters measured from 102 howling bouts of Guianan red howler monkeys at the Viruá National Park, Roraima, Brazil.

\begin{tabular}{ll}
\hline \multicolumn{1}{c}{ Acoustic Parameter } & \multicolumn{1}{c}{ Description } \\
\hline Mean frequency $(\mathrm{Hz})$ & Mean spectral frequency of call \\
Median frequency $(\mathrm{Hz})$ & Median spectral frequency of call \\
Dominant frequency $(\mathrm{Hz})$ & Frequency with highest energy in the call \\
Skewness & Spectral symmetry of call \\
Kurtosis & Spectral tailedness of call \\
First formant $(\mathrm{Hz})$ & First peak of energy in the call spectrum \\
Highest frequency $(\mathrm{Hz})$ & Upper frequency bound of the call \\
Harmonic-to-noise ratio $(\mathrm{dB})$ & Relative energy given to tonal versus atonal noise \\
Duration $(\mathrm{s})$ & Duration of continuous loud calling \\
\hline
\end{tabular}

\subsection{Statistics}

All statistical analyses were performed in R [41]. First, we used a chi-square goodness of fit test to evaluate whether nocturnal and diurnal calling events were equally common. Second, we used linear mixed models (LMM) to test for differences in diurnal and nocturnal bouts while controlling for group identity. In each LMM model, the dependent variable was one of nine acoustic parameters, the fixed effect was the period of the bout (diurnal or nocturnal), and the random effect was group identity. We fit nine individual models (restricted maximum likelihood) with the R package nlme [42]. Residuals of the models were checked for linearity, homoscedasticity, independence, and normality with the $\mathrm{R}$ package SjPlot [43]. We considered a fixed effect to be significant at $\alpha<0.05$. To avoid 
a Type I error due to multiple comparisons (testing the howling bouts multiple times), we lowered the alpha cutoff for significance using a sequential Bonferroni correction [44].

\section{Results}

\subsection{Automatic Detection and Diel Vocal Behavior}

A total of 171 howling bouts were automatically detected across ca. $5400 \mathrm{~h}$ of recordings. By comparing the validation dataset to the predictions, we obtained a recall rate of $42 \%$ with a precision of $100 \%$. The classifier mostly missed faint calls of howlers but never incorrectly classified other sound types as howling bouts. Howling bout emissions increased around $0300 \mathrm{~h}$ and peaked at $0500 \mathrm{~h}$, right before the nautical twilight (Figure 2). The Guianan red howler monkey was vocally active throughout the night but mostly silent during the day (Figure 2). The chi-square test confirmed that nocturnal calls were more common than diurnal calls $\left(\chi^{2}=23.21, \mathrm{df}=1, p<0.001\right)$.

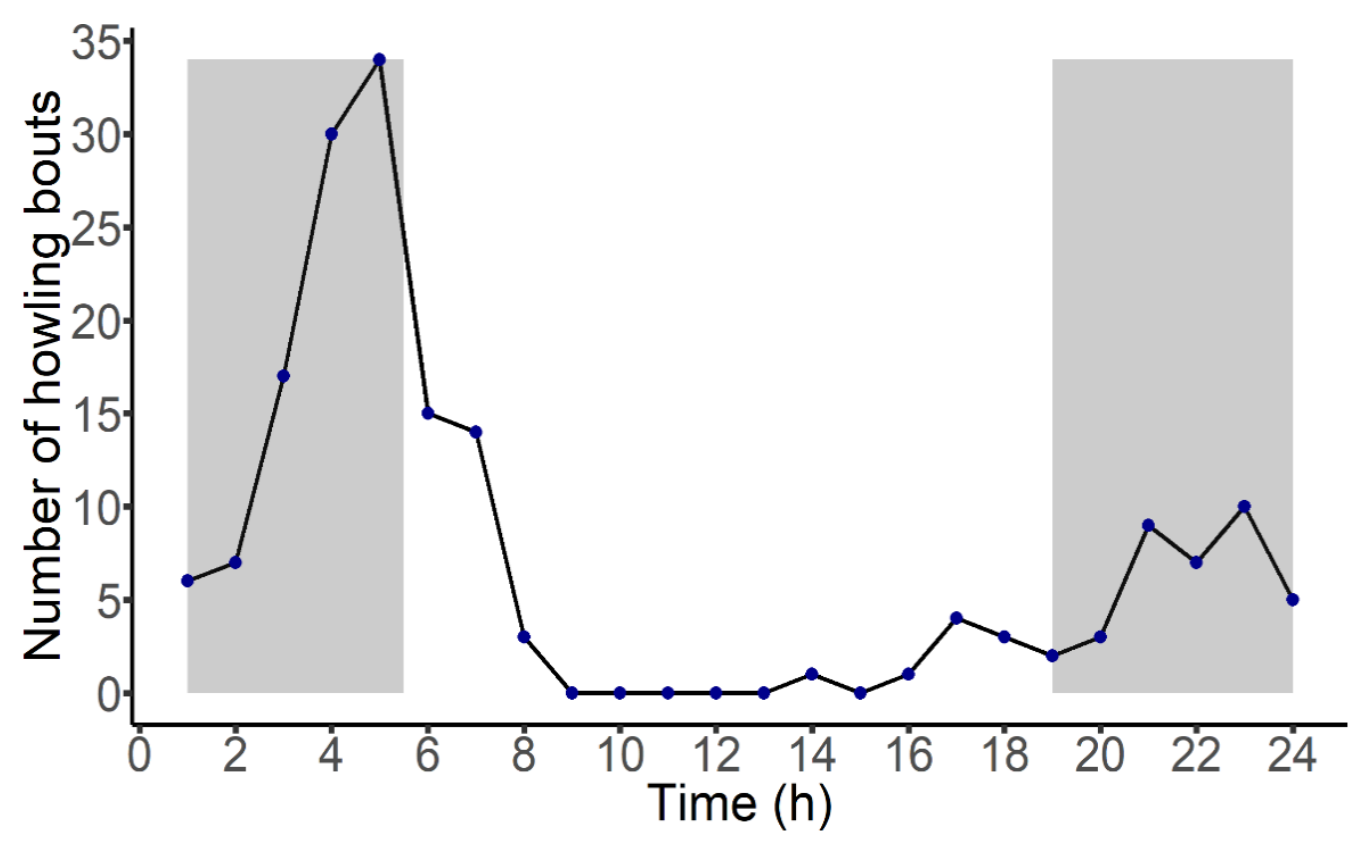

Figure 2. Diel vocal behavior of the Guianan red howler monkey in Viruá National Park, Roraima, Brazil. Diel pattern is expressed as the total number of howling bouts (all groups pooled) detected per recording hour. The graph starts at $0100 \mathrm{~h}$ and ends at $2400 \mathrm{~h}$. The gray shaded areas indicate nocturnal hours (1900 h to $0529 \mathrm{~h}$ ) based on nautical twilight.

\subsection{Differences between Diurnal and Nocturnal Howling Bouts}

The LMM revealed that diurnal and nocturnal howling bouts differed for six of the nine acoustic parameters (Table 4). Diurnal bouts were significantly longer than nocturnal bouts. The harmonic-to-noise ratio, skewness, kurtosis, first formant, and highest frequency parameters were all significantly lower in diurnal than nocturnal bouts (Figure 3). 
Table 4. Acoustic parameters (mean \pm SD) for nocturnal and diurnal howling bouts of Guianan red howlers and results for linear mixed models ( $t$ statistics and $p$ values are indicated).

\begin{tabular}{cccccc}
\hline Acoustic Parameter & $\begin{array}{c}\text { Diurnal } \\
\mathbf{( N = 5 1 )}\end{array}$ & $\begin{array}{c}\text { Nocturnal } \\
(\mathbf{N}=\mathbf{5 1})\end{array}$ & $\boldsymbol{t}$ & $\boldsymbol{p}^{\mathbf{a}}$ & $\boldsymbol{\alpha}^{\mathbf{b}}$ \\
\hline Mean frequency (Hz) & $1063 \pm 126$ & $1023 \pm 89$ & -1.77 & 0.070 & 0.630 \\
Median frequency (Hz) & $920 \pm 125$ & $895 \pm 89$ & -1.03 & 0.300 & 1 \\
Dominant frequency (Hz) & $696 \pm 264$ & $730 \pm 277$ & 0.11 & 0.900 & 1 \\
Skewness & $4.0 \pm 0.4$ & $4.3 \pm 0.4$ & 3.05 & $\mathbf{0 . 0 0 2}$ & $\mathbf{0 . 0 1 8}$ \\
Kurtosis & $20 \pm 4.5$ & $23 \pm 5$ & 3.06 & $\mathbf{0 . 0 0 3}$ & $\mathbf{0 . 0 2 7}$ \\
First formant (Hz) & $457 \pm 27$ & $494 \pm 19$ & 6.82 & $<\mathbf{0 . 0 0 1}$ & $<\mathbf{0 . 0 0 1}$ \\
Highest frequency (Hz) & $2495 \pm 68$ & $2569 \pm 37$ & 11.2 & $<\mathbf{0 . 0 1}$ & $<\mathbf{0 . 0 0 1}$ \\
Harmonic-to-noise ratio (dB) & $1.16 \pm 0.3$ & $2.01 \pm 0.4$ & -3.81 & $<\mathbf{0 . 0 0 1}$ & $<\mathbf{0 . 0 0 1}$ \\
Duration (s) & $327 \pm 93$ & $258 \pm 83$ &
\end{tabular}

${ }^{\text {a }}$ Significant results $(p<0.05)$ are in bold. ${ }^{\mathrm{b}} \alpha$ values were adjusted using a Bonferroni correction.

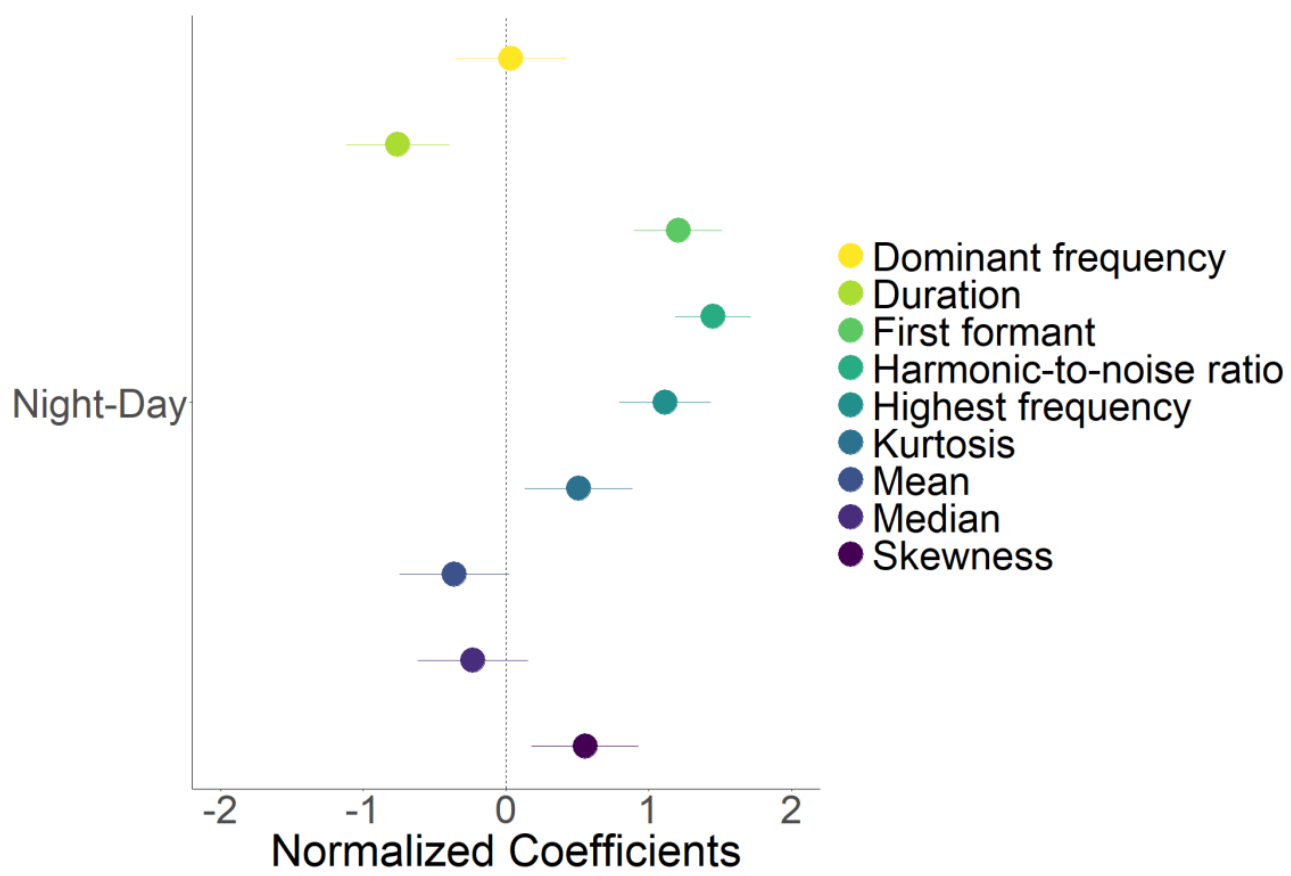

Figure 3. Results of linear mixed models showing the effect of the time howling bouts were emitted (night or day) on nine acoustic parameters. The reference level for the models (i.e., the intercept) was "day". Dots are the normalized coefficients values and lines represent the $95 \%$ confidence intervals. Coefficients were normalized by subtracting raw values by the mean and dividing by the standard deviation. Positive values indicate higher values for nocturnal howling bouts.

\section{Discussion}

Nocturnal vocalizations from diurnal primates have rarely been studied $[1,5,8,10,14]$. While previous research on the Guianan red howler monkey described different types of calls in their repertoire [15], a detailed and systematic description of their vocal behavior and howling bouts was lacking. Here, we provide a description of the diel pattern of vocal behavior and a comparison of the acoustic features of howling bouts during the day and night. We found that the Guianan red howler monkey vocalized mainly at night and remained silent for most of the day. Howling bouts made during the day differed in structure from those made at night primarily because, on average, they were $26 \%$ longer, had a $73 \%$ lower harmonic-to-noise ratio, had 5\% lower frequencies (first formant and highest frequency), and had more symmetric energy distributions (skewness and kurtosis). Our study provides additional evidence regarding the utility of PAM and automatic acoustic detection as useful tools to study patterns of activity of primates across their diel 
activity cycle $[22,23,45,46]$. PAM coupled with automatic detection of calls allowed us to monitor larger areas for longer periods and gain new insight into the behavioral ecology of this species.

The unimodal pattern of calling activity of Guianan howlers found in our study agrees with the typical diel pattern of vocal behavior described for several species in the genus, with most vocalizations concentrated around dawn [1]. Our findings regarding the diel vocal behavior of Guianan howlers in the Brazilian Amazon also agree with those found in a disjoint population in French Guiana [15]. The pioneering study in French Guiana also found a peak of activity around dawn, more howling bouts during the night, and silent periods during the day [15]. Interestingly, the howlers in French Guiana also seem to increase their howling bouts around $0300 \mathrm{~h}$ with a peak around $0700 \mathrm{~h}$, right before they are leaving their sleeping sites [15]. This suggests the existence of a common pattern in vocal activity for this howler species, even between populations on extreme sides of its distribution [47]. Future research could focus on the environmental and behavioral drivers of calling in this species and other howlers across their distribution using similar and standard methods (e.g., PAM surveys and automatic detection) to elucidate these patterns further [1].

Our PAM study coupled with automated acoustic detection displayed a lower detection rate than other studies found in the literature. We detected 0.03 howling bouts per hour while detection rates in other published studies (using PAM or aural surveys) monitoring three different howler species ranged between 0.06 and 0.14 ([48-50], see full discussion in [5]). The lower detection rate found in our study may be related to the classifier we built, which missed more than half of the howling bouts present in our validation dataset $(42 \%$ recall rate) despite its high precision (100\%) in not assigning other sound types as howling bouts. However, when comparing the diel pattern from our validation dataset to the one obtained with the automatic classification, we noted that despite the relatively low recall rate of the classifier, we were still able to get an accurate picture of the diel vocal behavior of the species because both datasets displayed a similar pattern (Figure 2 and Figure S7). In addition, a classifier with a high precision may well be more important to ecologists employing such technology than higher recall rates, for example, in occupancy modeling false positives are problematic to handle with the existing analytical methods but not false negatives [28,51]. Moreover, the differences in detection rates among studies also may be related to different sampling schemes, length of the studies, and number of howler groups monitored. Future studies should focus on disentangling the drivers of such differences and could explore ways to increase the recall rate of the classifier without losing precision. For example, since a human listener had to apply a $5 \mathrm{~dB}$ filter to all recordings to correctly classify the calls in our validation dataset, this filter could be applied to all recordings before the automatic classification to test if the recall rate would also increase. Nevertheless, we show how PAM and automatic classifiers work well in scanning large datasets and provide a reliable picture about the vocal activity of a poorly studied Neotropical primate $[5,26]$.

Vercauteren Drubbel and Gautier [15] observed longer howling bouts when the Guianan red howler monkeys were leaving their sleep trees in the morning. They also observed longer calls when the howler monkeys were arriving at their roosting sites in the afternoon. Although randomly selected, most of the diurnal calls analyzed belonged to the first and last few hours of light because that is when they largely call during the day (Figure S4), and these calls were longer than nocturnal calls (Table 4). Similar to Vercauteren Drubbel and Gautier [15], we speculate that the longer howling bouts during the day might be related to the monkeys indicating the time they are leaving their sleeping trees to forage and when they are coming back to sleep. Duration of vocalizations is indicative of effort, with longer vocalizations requiring more energy to produce $[52,53]$. These longer vocal displays preceding daily movements and indicating the return to roosting sites could be related to a mutual avoidance strategy between neighboring groups of howlers $[2,17,19,54]$. A similar behavior of longer loud calls during dawn and contests was observed in mantled howlers [18], black howlers [50,55], and baboons (Papio cynocephalus ursinus, [56]). 
Guianan red howlers increased the amount of deterministic chaos (as measured by the harmonic-to-noise ratio) during the day (Table 4). This acoustic characteristic leads to harsher calls that are more intimidating than tonal calls $[6,57,58]$. Across many mammals, vocalizations with more chaos have been shown either to elicit a reluctance to escalate a contest with a threatening male [59] or to make them respond more strongly to a conspecific [60]. The mechanism through which these responses may occur is unknown, but in chimpanzees, it is believed that the presence of non-linear phenomena, such as deterministic chaos in their loud calls, may be used to assess the physical condition of the caller [61]. Harsher howling bouts of the Guianan red howler monkey may also serve to more efficiently intimidate other groups, increase the chance of winning contests, and thus avoid the more energetic costs of chases and fights. Previous studies have speculated that sporadic roars of the black howler and the black-and-gold howler monkey emitted during the day might be related to neighboring groups getting in closer range to each other $[5,50,54]$. During such vocal contests and sporadic encounters during the day, the Guianan red howler may utter more intimidating (harsher) calls, which may explain our results.

The lower pitch of howling bouts during the day than at night may also reflect a greater motivation to intimidate neighboring groups [57,62-64]. Because animals may modify the pitch of their calls to signal competitive abilities [52,65], lower-pitch calls may be better at intimidating other groups during contests [57]. However, it is important to note that changes in pitch between diurnal and nocturnal howling bouts were of a smaller magnitude than the duration and the harmonic-to-noise ratio, suggesting that they may play a smaller role in intergroup competition or that they are harder to modify due to morphological constraints [66]. Further research is required to understand under which circumstances the Guianan red howler monkey, or other primates, are able to modify acoustic features for communication.

More detailed approaches (e.g., recording individuals with directional microphones at known distances) are needed to corroborate our findings about the acoustic differences between night and day. This is an important limitation in PAM studies, difficulties arise by not knowing the precise distance between the microphones and target individual. We tried to overcome this limitation with field observations and a careful selection of loud calls used in the analysis. Another important limitation of this study is that we surveyed the Guianan howlers only during the dry season. Both the vocal behavior and the classifier performance may change over the rainy season (i.e., due to changes in the breeding status of the species and background noise).

Future research should try to elucidate the mechanisms behind the patterns found in our study and answer some of the new questions that may arise. For example: (1) Are the species calling more at night due to better sound transmission during this time (e.g., higher humidity, less wildlife vocalizing at night)? (2) Are there seasonal differences in howling bouts emissions? Playback experiments, coupled with field observations of the species, could also be employed to test for functional differences between howling bouts emitted at different times (e.g., night and day) and evaluate how different individuals (e.g., males and females) respond towards the broadcasted vocalizations.

In conclusion, in this study, we provide a detailed analysis of the Guianan red howler vocal behavior and explore differences between diurnal and nocturnal howling bouts using PAM coupled with automatic acoustic detection and field observations. We show that this species vocalizes throughout the night, with a peak of vocal activity before nautical twilight, and remains silent for most of the day. Vocalizations during the day might be associated with neighboring groups getting in close range, and howlers responding by producing longer and harsher (more intimidating) bouts. Overall, this study highlights the importance of studying animals throughout the full diel cycle to uncover the full spectrum of their behavioral ecology. This is now facilitated through remote sensing methods, such as camera trapping and PAM [23,25], which hold great potential to tackle the difficulties associated with studying primates and nocturnal patterns in ecology $[5,8,9]$. 
Supplementary Materials: The following are available online at https: / www.mdpi.com/article/ 10.3390/d13110566/s1, Figure S1: studied area and howler groups; Figure S2: template used in the automatic classification; Figure S3: examples of howling bouts; Figure S4: Temporal distribution of the 102 howling bouts used in our acoustic analysis; Figure S5: examples of background noise at night and day; Figure S6: shows how the formants were calculated; Figure S7: diel vocal behavior from the manual validation dataset.

Author Contributions: Formal analysis, L.A.D.N.; Funding acquisition, L.A.D.N. and K.H.B.; Investigation, L.A.D.N.; Methodology, L.A.D.N. and K.H.B.; Writing-original draft, L.A.D.N.; Writingreview and editing, C.P.-G. and K.H.B.; Supervision, K.H.B. All authors have read and agreed to the published version of the manuscript.

Funding: This research was supported by grants from: the Rufford Foundation, United Kingdom (\#24612-1); the Ecology Center, Utah State University; a fellowship to LAN (Ciências sem Fronteiras -Conselho Nacional de Desenvolvimento Científico e Tecnológico \#203230/2015-9) from Brazil; and the Utah Agricultural Experiment Station, Utah State University, approved as journal paper \#9284.

Institutional Review Board Statement: Research complied with protocols approved by Utah State University's Animal Care and Use Committee (IACUC \#2690) and all Brazilian legal requirements (SISBIO license \#56539-2).

Data Availability Statement: The data that support the findings of this study will be available on figshare upon publication (10.6084/m9.figshare.14481396).

Acknowledgments: We would like to thank the people who facilitated this work such as the local field assistants Max, Cobra, and Netão. We are grateful to all communities living around the VNP and especially to Beatriz Ribeiro (Director of VNP) for all her support of this research. We also would like to thank Susan Durham for valuable statistical advice and two anonymous reviewers whose comments helped to improve the manuscript.

Conflicts of Interest: The authors declare no conflict of interest. The funders had no role in the design of the study; in the collection, analyses, or interpretation of data; in the writing of the manuscript, or in the decision to publish the results.

\section{References}

1. Da Cunha, R.G.T.; de Oliveira, D.A.G.; Holzmann, I.; Kitchen, D.M. Production of Loud and Quiet Calls in Howler Monkeys. In Howler Monkeys; Springer: New York, NY, USA, 2015; pp. 337-368. [CrossRef]

2. Kitchen, D.M.; da Cunha, R.G.T.; Holzmann, I.; de Oliveira, D.A.G. Function of Loud Calls in Howler Monkeys. In Howler Monkeys; Springer: New York, NY, USA, 2015; pp. 369-399. [CrossRef]

3. Gil-da-Costa, R.; Palleroni, A.; Hauser, M.D.; Touchton, J.; Kelley, J.P. Rapid Acquisition of an Alarm Response by a Neotropical Primate to a Newly Introduced Avian Predator. Proc. Biol. Sci. 2003, 270, 605-610. [CrossRef]

4. Steinmetz, S. Vocalizações de Longo Alcance Como Comunicação Intra-Grupal Nos Bugios (Alouatta guariba). Neotrop. Primates 2005, 13, 11. [CrossRef]

5. Pérez-Granados, C.; Schuchmann, K.-L. Passive Acoustic Monitoring of the Diel and Annual Vocal Behavior of the Black and Gold Howler Monkey. Am. J. Primatol. 2021, 83, e23241. [CrossRef] [PubMed]

6. Bergman, T.J.; Cortés-Ortiz, L.; Dias, P.A.D.; Ho, L.; Adams, D.; Canales-Espinosa, D.; Kitchen, D.M. Striking Differences in the Loud Calls of Howler Monkey Sister Species (Alouatta pigra and A. palliata). Am. J. Primatol. 2016, 78, 755-766. [CrossRef] [PubMed]

7. Briseño-Jaramillo, M.; Biquand, V.; Estrada, A.; Lemasson, A. Vocal Repertoire of Free-Ranging Black Howler Monkeys' (Alouatta pigra): Call Types, Contexts, and Sex-Related Contributions. Am. J. Primatol. 2017, 79, e22630. [CrossRef] [PubMed]

8. Gaston, K.J. Nighttime Ecology: The "Nocturnal Problem" Revisited. Am. Nat. 2019, 193, 481-502. [CrossRef]

9. Cox, D.T.C.; Gardner, A.S.; Gaston, K.J. Diel Niche Variation in Mammals Associated with Expanded Trait Space. Nat. Commun. 2021, 12, 1753. [CrossRef]

10. Ankel-Simons, F.; Rasmussen, D.T. Diurnality, Nocturnality, and the Evolution of Primate Visual Systems. Am. J. Phys. Anthropol. 2008, 137 (Suppl. S47), 100-117. [CrossRef]

11. Parga, J.A. Nocturnal Ranging by a Diurnal Primate: Are Ring-Tailed Lemurs (Lemur catta) Cathemeral? Primates 2011, 52, 201-205. [CrossRef]

12. La, V.T. Diurnal and Nocturnal Birds Vocalize at Night: A Review. Condor 2012, 114, 245-257. [CrossRef]

13. Tan, C.L.; Yang, Y.; Niu, K. Into the Night: Camera Traps Reveal Nocturnal Activity in a Presumptive Diurnal Primate, Rhinopithecus brelichi. Primates 2013, 54,1-6. [CrossRef] 
14. Piel, A.K. Temporal Patterns of Chimpanzee Loud Calls in the Issa Valley, Tanzania: Evidence of Nocturnal Acoustic Behavior in Wild Chimpanzees. Am. J. Phys. Anthropol. 2018, 166, 530-540. [CrossRef] [PubMed]

15. Vercauteren Drubbel, V.; Gautier, J.P. On the Occurrence of Nocturnal and Diurnal Loud Calls, Differing in Structure and Duration, in Red Howlers (Alouatta seniculus) of French Guyana. Folia Primatol. 1993, 60, 195-209. [CrossRef]

16. Tagg, N.; McCarthy, M.; Dieguez, P.; Bocksberger, G.; Willie, J.; Mundry, R.; Stewart, F.; Arandjelovic, M.; Widness, J.; Landsmann, A.; et al. Nocturnal Activity in Wild Chimpanzees (Pan troglodytes): Evidence for Flexible Sleeping Patterns and Insights into Human Evolution. Am. J. Phys. Anthropol. 2018, 166, 510-529. [CrossRef]

17. Chivers, D.J. On the Daily Behaviour and Spacing of Howling Monkey Groups. Folia Primatol. 1969, 10, 48-102. [CrossRef] [PubMed]

18. Sekulic, R. Daily and Seasonal Patterns of Roaring and Spacing in Four Red Howler Alouatta seniculus Troops. Folia Primatol. 1982, 39, 22-48. [CrossRef] [PubMed]

19. Whitehead, J.M. Vocally Mediated Reciprocity between Neighbouring Groups of Mantled Howling Monkeys, Alouatta palliata Palliata. Anim. Behav. 1987, 35, 1615-1627. [CrossRef]

20. Kalan, A.K.; Mundry, R.; Wagner, O.J.J.; Heinicke, S.; Boesch, C.; Kühl, H.S. Towards the Automated Detection and Occupancy Estimation of Primates Using Passive Acoustic Monitoring. Ecol. Indic. 2015, 54, 217-226. [CrossRef]

21. Sugai, L.S.M.; Silva, T.S.F.; Ribeiro, J.W., Jr.; Llusia, D. Terrestrial Passive Acoustic Monitoring: Review and Perspectives. Bioscience 2019, 69, 15-25. [CrossRef]

22. Clink, D.J.; Klinck, H. Unsupervised Acoustic Classification of Individual Gibbon Females and the Implications for Passive Acoustic Monitoring. Methods Ecol. Evol. 2021, 12, 328-341. [CrossRef]

23. Deichmann, J.L.; Acevedo-Charry, O.; Barclay, L.; Burivalova, Z.; Campos-Cerqueira, M.; d'Horta, F.; Game, E.T.; Gottesman, B.L.; Hart, P.J.; Kalan, A.K.; et al. It's Time to Listen: There Is Much to Be Learned from the Sounds of Tropical Ecosystems. Biotropica 2018, 50, 713-718. [CrossRef]

24. Darras, K.; Batáry, P.; Furnas, B.J.; Grass, I.; Mulyani, Y.A.; Tscharntke, T. Autonomous Sound Recording Outperforms Human Observation for Sampling Birds: A Systematic Map and User Guide. Ecol. Appl. 2019, 29, e01954. [CrossRef] [PubMed]

25. Do Nascimento, L.A.; Campos-Cerqueira, M.; Beard, K.H. Acoustic Metrics Predict Habitat Type and Vegetation Structure in the Amazon. Ecol. Indic. 2020, 117, 106679. [CrossRef]

26. Aide, T.M.; Corrada-Bravo, C.; Campos-Cerqueira, M.; Milan, C.; Vega, G.; Alvarez, R. Real-Time Bioacoustics Monitoring and Automated Species Identification. PeerJ 2013, 1, e103. [CrossRef] [PubMed]

27. ICMBio. Instituto Chico Mendes de Conservação da Biodiversidade. Plano de Manejo do Parque Nacional do Viruá. ICMBio, Boa Vista, Roraima. Available online: http:/ /www.icmbio.gov.br/portal/images/stories/docs-planos-de-manejo/parna_virua_ pm_diag1.pdf (accessed on 10 January 2020).

28. Campos-Cerqueira, M.; Aide, T.M. Improving Distribution Data of Threatened Species by Combining Acoustic Monitoring and Occupancy Modelling. Methods Ecol. Evol. 2016, 7, 1340-1348. [CrossRef]

29. Audacity Team. Audacity Software 2.4.1; Audacity Team: Pittsburg, PA, USA, 2019.

30. Hafner, S.; Katz, J. monitoR: Acoustic Template Detection in R. Available online: http://www.uvm.edu/rsenr/vtcfwru/R/ ?Page $=$ monitoR/monitoR.htm (accessed on 20 March 2019).

31. Katz, J.; Hafner, S.D.; Donovan, T. Tools for Automated Acoustic Monitoring within the R Package MonitoR. Bioacoustics 2016, 25, 197-210. [CrossRef]

32. Ducrettet, M.; Forget, P.M.; Ulloa, J.S.; Yguel, B.; Gaucher, P.; Princé, K.; Haupert, S.; Sueur, J. Monitoring Canopy Bird Activity in Disturbed Landscapes with Automatic Recorders: A Case Study in the Tropics. Biol. Conserv. 2020, 245, 108574. [CrossRef]

33. Mellinger, D.K.; Clark, C.W. Methods for Automatic Detection of Mysticete Sounds. Mar. Freshw. Behav. Physiol. 1997, $29,163-181$. [CrossRef]

34. Priyadarshani, N.; Marsland, S.; Castro, I. Automated Birdsong Recognition in Complex Acoustic Environments: A Review. J. Avian Biol. 2018, 49, jav-01447. [CrossRef]

35. Le Tallec, T.; Perret, M.; Théry, M. Light Pollution Modifies the Expression of Daily Rhythms and Behavior Patterns in a Nocturnal Primate. PLoS ONE 2013, 8, e79250. [CrossRef] [PubMed]

36. Foote, J.R.; Nanni, L.K.; Schroeder, R. Seasonal Patterns of Nocturnal Singing by Ovenbirds and White-Throated Sparrows. Behaviour 2017, 154, 1275-1295. [CrossRef]

37. Sueur, J.; Aubin, T.; Simonis, C. Seewave, a Free Modular Tool for Sound Analysis and Synthesis. Bioacoustics 2008, 18, 213-226. [CrossRef]

38. Tokuda, I.; Riede, T.; Neubauer, J.; Owren, M.J.; Herzel, H. Nonlinear Analysis of Irregular Animal Vocalizations. J. Acoust. Soc. Am. 2002, 111, 2908-2919. [CrossRef]

39. Boersma, P.; Weenink, D. Praat Software; Praat: Amsterdam, The Netherlands, 2013.

40. Dunn, J.C.; Halenar, L.B.; Davies, T.G.; Cristobal-Azkarate, J.; Reby, D.; Sykes, D.; Dengg, S.; Fitch, W.T.; Knapp, L.A. Evolutionary Trade-off between Vocal Tract and Testes Dimensions in Howler Monkeys. Curr. Biol. 2015, 25, 2839-2844. [CrossRef]

41. R Core Team. A Language and Environment for Statistical Computing; R Foundation for Statistical Computing: Vienna, Austria, 2020.

42. Pinheiro, J.; Bates, D.; DebRoy, S.; Sarkar, D.; Team, R.C. Nlme: Linear and Nonlinear Mixed Effects Models. Available online: https:/ / svn.r-project.org/R-packages/trunk/nlme (accessed on 20 March 2020). 
43. Lüdecke, D. sjPlot: Data Visualization for Statistics in Social Science. Available online: https://strengejacke.github.io/sjPlot/ (accessed on 20 March 2020).

44. Holm, S. Simple sequentially rejective multiple test procedure. Scand. Stat. Theory Appl. 1979, 6, 65-70. Available online: https:/ / www.jstor.org/stable/4615733 (accessed on 20 February 2020).

45. Heinicke, S.; Kalan, A.K.; Wagner, O.J.; Mundry, R.; Lukashevich, H.; Kühl, H.S. Assessing the performance of a semi-automated acoustic monitoring system for primates. Methods Ecol. Evol. 2015, 6, 753-763. [CrossRef]

46. Enari, H.; Enari, H.S.; Okuda, K.; Maruyama, T.; Okuda, K.N. An Evaluation of the Efficiency of Passive Acoustic Monitoring in Detecting Deer and Primates in Comparison with Camera Traps. Ecol. Indic. 2019, 98, 753-762. [CrossRef]

47. Boubli, J.P.; Urbani, B. Alouatta macconnelli. The IUCN Red List of Threatened Species 2021: E.T198622924A198669499. Available online: https:/ / www.iucnredlist.org/species/198622924/198669499 (accessed on 23 April 2021).

48. Chiarello, A.G. Role of Loud Calls in Brown Howlers, Alouatta fusca. Am. J. Primatol. 1995, 36, 213-222. [CrossRef]

49. Da Cunha, R.G.T.; Byrne, R.W. Roars of Black Howler Monkeys (Alouatta caraya): Evidence for a Function in Inter-Group Spacing. Behaviour 2006, 143, 1169-1199. [CrossRef]

50. Van Belle, S.; Estrada, A.; Garber, P.A. Spatial and Diurnal Distribution of Loud Calling in Black Howlers (Alouatta pigra). Int. J. Primatol. 2013, 34, 1209-1224. [CrossRef]

51. Balantic, C.; Donovan, T. Dynamic Wildlife Occupancy Models Using Automated Acoustic Monitoring Data. Ecol. Appl. 2019, 29, e01854. [CrossRef]

52. Fischer, J.; Kitchen, D.M.; Seyfarth, R.M.; Cheney, D.L. Baboon Loud Calls Advertise Male Quality: Acoustic Features and Their Relation to Rank, Age, and Exhaustion. Behav. Ecol. Sociobiol. 2004, 56, 140-148. [CrossRef]

53. Vannoni, E.; McElligott, A.G. Fallow Bucks Get Hoarse: Vocal Fatigue as a Possible Signal to Conspecifics. Anim. Behav. 2009, 78, 3-10. [CrossRef]

54. Van Belle, S.; Estrada, A. The Influence of Loud Calls on Intergroup Spacing Mechanism in Black Howler Monkeys (Alouatta pigra). Int. J. Primatol. 2020, 41, 265-286. [CrossRef]

55. Kitchen, D.M. Alpha Male Black Howler Monkey Responses to Loud Calls: Effect of Numeric Odds, Male Companion Behaviour and Reproductive Investment. Anim. Behav. 2004, 67, 125-139. [CrossRef]

56. Kitchen, D.M.; Seyfarth, R.M.; Fischer, J.; Cheney, D.L. Loud Calls as Indicators of Dominance in Male Baboons (Papio cynocephalus ursinus). Behav. Ecol. 2013, 53, 374-384. [CrossRef]

57. Morton, E.S. On the Occurrence and Significance of Motivation-Structural Rules in Some Bird and Mammal Sounds. Am. Nat. 1977, 111, 855-869. [CrossRef]

58. Demartsev, V.; Bar Ziv, E.; Shani, U.; Goll, Y.; Koren, L.; Geffen, E. Harsh Vocal Elements Affect Counter-Singing Dynamics in Male Rock Hyrax. Behav. Ecol. 2016, 27, 1397-1404. [CrossRef]

59. Garcia, M.; Wyman, M.T.; Charlton, B.D.; Fitch, W.T.; Reby, D. Response of Red Deer Stags (Cervus elaphus) to Playback of Harsh versus Common Roars. Sci. Nat. 2014, 101, 851-854. [CrossRef]

60. Townsend, S.W.; Manser, M.B. The Function of Nonlinear Phenomena in Meerkat Alarm Calls. Biol. Lett. 2011, 7, 47-49. [CrossRef]

61. Riede, T.; Arcadi, A.C.; Owren, M.J. Nonlinear Acoustics in the Pant Hoots of Common Chimpanzees (Pan troglodytes): Vocalizing at the Edge. J. Acoust. Soc. Am. 2007, 121, 1758-1767. [CrossRef]

62. Reby, D.; McComb, K. Anatomical Constraints Generate Honesty: Acoustic Cues to Age and Weight in the Roars of Red Deer Stags. Anim. Behav. 2003, 65, 519-530. [CrossRef]

63. Ordóñez-Gómez, J.D.; Dunn, J.C.; Arroyo-Rodríguez, V.; Méndez-Cárdenas, M.G.; Márquez-Arias, A.; Santillán-Doherty, A.M. Role of Emitter and Severity of Aggression Influence the Agonistic Vocalizations of Geoffroy's Spider Monkeys (Ateles geoffroyi). Int. J. Primatol. 2015, 36, 429-440. [CrossRef]

64. Mercier, S.; Déaux, E.C.; van de Waal, E.; Bono, A.E.J.; Zuberbühler, K. Correlates of Social Role and Conflict Severity in Wild Vervet Monkey Agonistic Screams. PLoS ONE 2019, 14, e0214640. [CrossRef] [PubMed]

65. Whitehead, J.M. Acoustic Correlates of Social Contexts and Inferred Internal States in Howling Monkeys (Alouatta palliata). J. Acoust. Soc. Am. 1992, 91, 2465. [CrossRef]

66. Kitchen, D.M.; Bergman, T.J.; Dias, P.A.D.; Ho, L.; Canales-Espinosa, D.; Cortés-Ortiz, L. Temporal but Not Acoustic Plasticity in Hybrid Howler Monkey (Alouatta palliata $\times$ A. pigra) Loud Calls. Int. J. Primatol. 2019, 40, 132-152. [CrossRef] 